\title{
Shaft friction changes for cyclically loaded displacement piles: an X-ray investigation
}

\author{
J. DOREAU-MALIOCHE*, G. COMBE*, G. VIGGIANI* and J. B. TONI*
}

\begin{abstract}
The mechanisms occurring at the grain scale at sand-pile interface under axial cyclic loading are analysed quantitatively in a mini calibration chamber, using X-ray tomography and three-dimensionaldigital image correlation. Grain kinematics and porosity evolution are followed along with the macroscopic mechanical response of the interface. The results show different phases in the evolution of shaft resistance during cyclic loading, with a non-negligible increase of shaft resistance in the latter phase. The test conditions are not representative of real engineering applications, where piles supporting bridges, tidal or wind turbines have to safely sustain severe load-controlled cycles. However, advanced image analysis sheds light on the mechanisms controlling the macroscopic behaviour of sand-pile interface. This study provides valuable data set against which theoretical or numerical approaches can be tested.
\end{abstract}

KEYWORDS: laboratory tests; particle-scale behaviour; soil/structure interaction

Published with permission by the ICE under the CC-BY 4.0 license. (http://creativecommons.org/licenses/by/4.0/)

\section{INTRODUCTION}

The mechanisms controlling the macroscopic behaviour of sand-pile interface during pile installation and cyclic loading are complex and are difficult to fully understand from field observations. Jardine \& Standing (2000, 2012) reported results of multiple axial cyclic loading tests conducted on steel open-ended pipe piles driven in sand, at Dunkerque, northern France. The authors identified three kinds of responses (stable, unstable and meta-stable), depending on the mean shaft load, the shaft cyclic amplitude and the number of cycles. They also noted that a large number of low-level stable cycles can have beneficial effects on shaft capacity, whereas high-level cycles can lead to shaft failure and halving of the axial capacity within a few tens of cycles. As part of the national project SOLlicitations CYcliques sur Pieux de fondation (SOLCYP), Benzaria et al. (2013) obtained the same trends for bored piles installed in dense Flanders sands, at Loon Plage, northern France. A remarkable laboratory investigation using a pressurised calibration chamber was performed in the framework of a combined research effort by Laboratoire 3SR and Imperial College London (Rimoy et al., 2015; Tsuha et al., 2012; Silva, 2014). The results, compatible with those obtained in the field, offer further insights into the local effective stress paths developed during cycling.

In a number of recent contributions, the behaviour of soil-pile interfaces has been studied by means of DEM simulations (Jiang et al., 2006; Lobo-Guerrero \& Vallejo, 2007; Butlanska et al., 2014). However, the authors are not aware of any equivalent experimental study. Numerous laboratory investigations have been reported on related topics of sand kinematics, grain crushing, local porosity changes and macroscopic interface behaviour (White \& Bolton, 2002; Yang et al., 2010; Silva et al., 2013; Arshad et al., 2014).

Manuscript received 26 October 2017; first decision 30 January 2018; accepted 31 January 2018.

Published online at www.geotechniqueletters.com on 21 March 2018.

*Université Grenoble Alpes, CNRS, Grenoble INP (Institute of Engineering Université Grenoble Alpes), 3SR, Grenoble, France.
The mechanisms controlling the macroscopic response of the interface were observed either post-mortem or in plane strain and mainly during pile installation.

This work focuses on the sand grains behaviour in the vicinity of a pile during axial cyclic loading. The tests are performed in a mini calibration chamber installed in an $\mathrm{X}$-ray scanner. The pile is installed by jacking and submitted to 1000 displacement-controlled cycles under constant radial stress. The tests do not represent accurately real engineering applications, where piles supporting bridges, tidal or wind turbines are subjected to load-controlled cycles due to their environment. However, the combined use of threedimensional (3D) tomographic imaging and advanced tools such as 3D-digital image correlation (DIC), allows us to obtain quantitative information at the grain scale and offers valuable data set against which theoretical or numerical approaches can be tested.

\section{MATERIAL AND EXPERIMENTAL SET-UP}

The tests are carried out inside the X-ray scanner of Laboratoire 3SR, in Grenoble, France. The chamber consists of a cylindrical cell transparent to X-rays in order to image the deformation of the sample while running a test (Fig. 1). The soil used for this study is Glageon sand, whose index properties are summarised in Table 1. Glageon sand is a calcareous sand derived from limestone rock crushed in Bocahut quarry, France, with $D_{50}=1.125 \mathrm{~mm}$ and a relatively uniform grading (between 1.00 and $1.25 \mathrm{~mm}$ ). Grains are large enough to be identified and tracked individually from one image to another (see Section 'X-ray Tomography and 3D-DIC'). The angular and elongated shape of the grains of Glageon sand makes them highly crushable, which is the main reason they were selected for this study. In this paper, results from three nominally identical tests (GLAG-C1, GLAG-C2, GLAG-C3) are presented. The samples are dry and their initial relative density ranges from 70 to $90 \%$. At this relative density, triaxial compression tests give $\varphi^{\prime}$ values of $48^{\circ}$.

The cone-ended model pile is made of aluminium, due to its very low X-ray absorption coefficient. The diameter of 


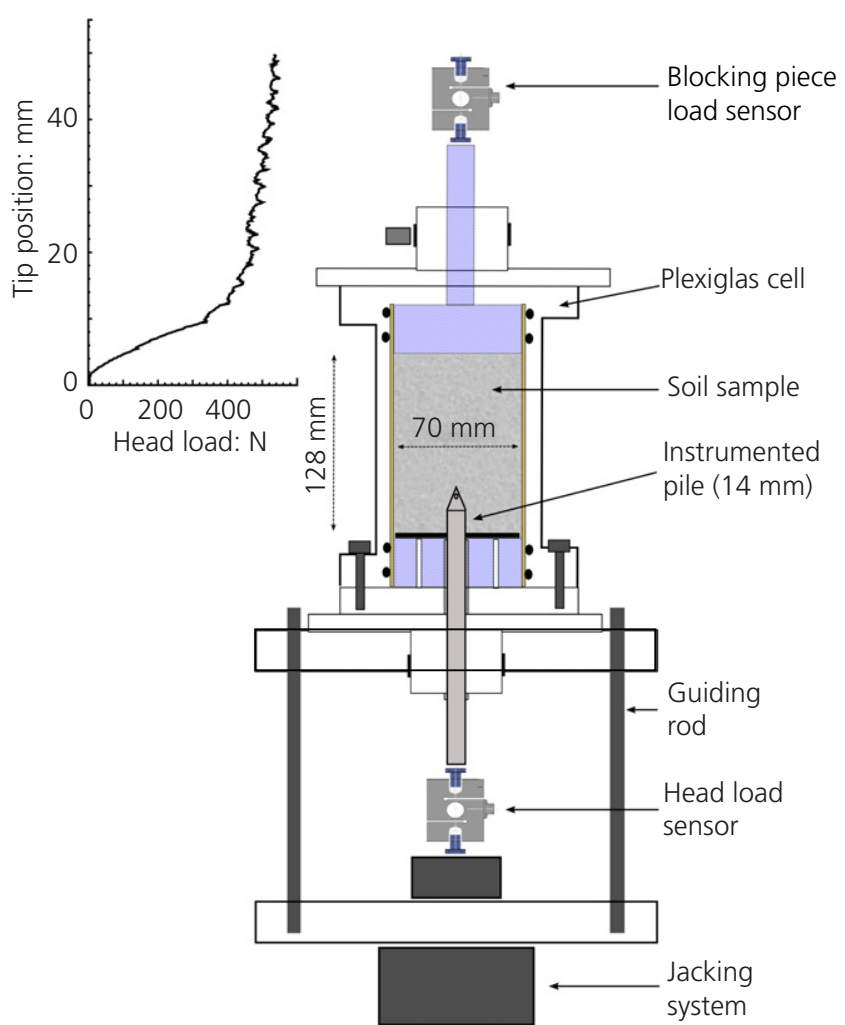

Fig. 1. Experimental equipment and a typical head load profile (top left) during pile installation

Table 1. Glageon sand properties

\begin{tabular}{l|l|l|l|l|l}
\hline $\begin{array}{l}\text { Grain } \\
\text { shape }\end{array}$ & $\begin{array}{l}\text { Specific } \\
\text { gravity }\left(G_{\mathrm{s}}\right)\end{array}$ & $\begin{array}{l}D_{50}: \\
\mathrm{mm}\end{array}$ & $\begin{array}{l}\text { Coefficient of } \\
\text { uniformity } C_{\mathrm{u}}\end{array}$ & $e_{\max }$ & $e_{\min }$ \\
\hline Angular & 2.65 & $1 \cdot 125$ & 1.25 & 1.070 & 0.839 \\
\hline
\end{tabular}

$14 \mathrm{~mm}$ allows for its instrumentation with a load sensor at its end to measure the tip load. The total load applied on the pile is measured thanks to the head load sensor. By subtracting the tip load from the total load, the shaft capacity is also measured. The model pile has a smooth surface with a roughness of about $0 \cdot 7 \mu \mathrm{m}$. The roughness of sand-pile interface is known to be one of the most important factors affecting the unit shaft resistance (Fioravante, 2002; Hebeler et al., 2015; Tehrani et al., 2016). Uesugi et al. (1988) also showed the effect of the roughness of the interface on the formation of a shear band in the vicinity of the interface. They noted that sand particles tend to slide along a smooth surface without large deformation. Therefore, in this study, the friction mobilised by the shaft is lower than the one measured in the field. Direct shear tests on sand-aluminium interface give $\delta^{\prime}=15^{\circ}$ whereas field piles have a roughness that leads to a typical $\delta^{\prime}$ of about $30^{\circ}$.

The pile is installed by jacking at a rate of $25 \mu \mathrm{m} / \mathrm{s}$ until an initial embedment depth (either 50 or $60 \mathrm{~mm}$ ) under an isotropic stress of $100 \mathrm{kPa}$ (see Fig. 1). Note that, for practical reasons, the pile is installed from the bottom of the cell, that is, it moves upwards. Following the installation phase, the pile is submitted to 1000 axial displacementcontrolled cycles. The cycles are performed at the same rate as for pile installation, with an amplitude of $\pm 0.5 \mathrm{~mm}$ around the pile-tip reference position, alternating between compression and tension phases (two-way cycles).

\section{SCALE EFFECTS}

At earth gravity, the main effect to be considered for small-scale calibration chambers is that of chamber boundaries. In fact, except in the very specific case of 'active' boundary conditions (i.e. under constant normal stiffness) pile behaviour is very sensitive to the ratio of the chamber diameter to the pile diameter (Parkin \& Lunne, 1982; Been et al., 1986; Boulon \& Foray, 1986; Foray, 1991). Schnaid \& Houlsby (1991) reported that this ratio should be higher than 50 for dense sands. More recently, Salgado et al. (1998) suggested that higher values $(>100)$ may be required in order to reach complete similitude with field behaviour.

A second important source of scale effects in model pile tests is the ratio of the pile diameter to the mean particle size. In the case of a coarse sand, the layer of grains around the shaft experiencing shearing becomes too large, which can lead to excessive normal effective stress and affect directly the shaft resistance as reported by Lee et al. (2011). To minimise this effect the pile diameter should be at least 80 times the mean particle size according to Peterson (1988).

In this study, the ratio of the chamber to the pile diameter and the ratio of the pile diameter to the mean particle size are, respectively, 5 and 14, which is far below the limits proposed in the literature and cannot reproduce field conditions. This design was selected in order to access new information at the grain scale and was restricted by the imaging tools.

\section{MACROSCOPIC RESPONSE OF THE INTERFACE}

Figure 2(a) shows the evolution of the total load applied to the pile against tip position as measured in test GLAG-C1. When tip position goes from -0.5 to $+0.5 \mathrm{~mm}$, three different phases are observed after the first two cycles or so. At the very beginning of each cycle (phase I), the measured response is very stiff, which is expected due to load direction reversal. A sudden change in slope is then observed (phase II), which becomes more important after 50 cycles. The load increases slightly with a smaller tangential stiffness and less rapidly till a tip position of around $-0 \cdot 1 \mathrm{~mm}$, thereafter it starts increasing again (phase III). Li et al. (2012) observed relatively similar response, with three different phases, in the case of pre-jacked piles. They attributed the softening behaviour observed during the second phase to a high densification of the sand at the pile base. In this study, tomographic images taken at different stages of the loading reveal that in fact a gap forms between the pile tip and the grains, due to a high densification of the sand ahead of the pile tip. This phenomenon indicates that during phase I, the head load is only due to the friction on the shaft, while the tip is completely unloaded. Once the friction is mobilised, the head load does not vary significantly (phase II) until the tip comes again in contact with the grains (phase III).

Figure 2(b) shows the shaft resistance during the cycles. Two different phases can be identified. For the first 50 to 100 cycles, shaft friction slightly decreases (of about $15 \mathrm{~N}$ ), whereas it increases continuously and significantly for the subsequent load cycles. When the tip is at $\pm 0.5 \mathrm{~mm}$, the curves show a peak, which become increasingly marked with increasing number of cycles.

Figure 3 presents the force induced by friction measured at the peak for various tests performed on Glageon sand, with identical testing parameters. The shaft resistance at the end of the cycles is twice as big as the value measured during the first cycle. The transition between the two phases occurs at 50-100 cycles (shaded region in the figure). From displacement controlled calibration chamber model pile tests, Silva (2014) and Bekki et al. (2016) obtained similar results but 


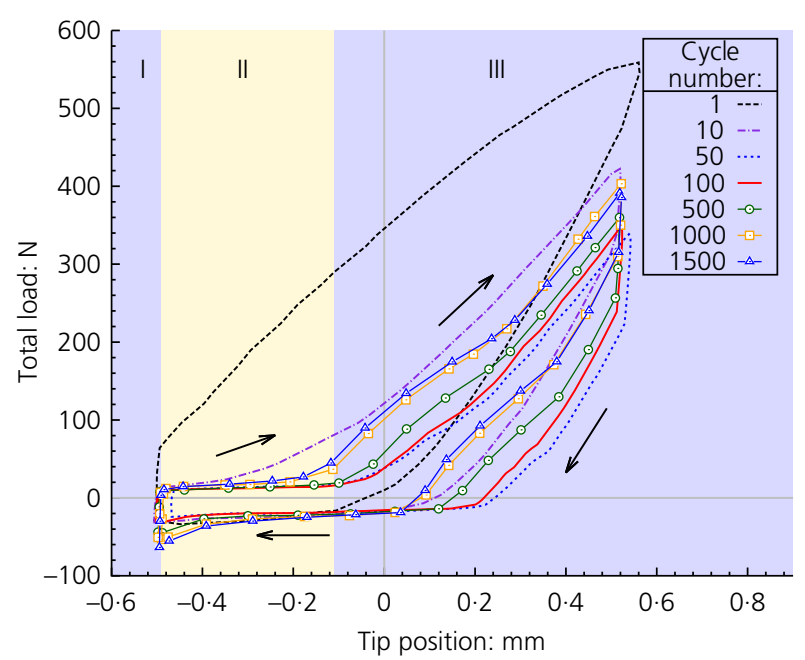

(a)

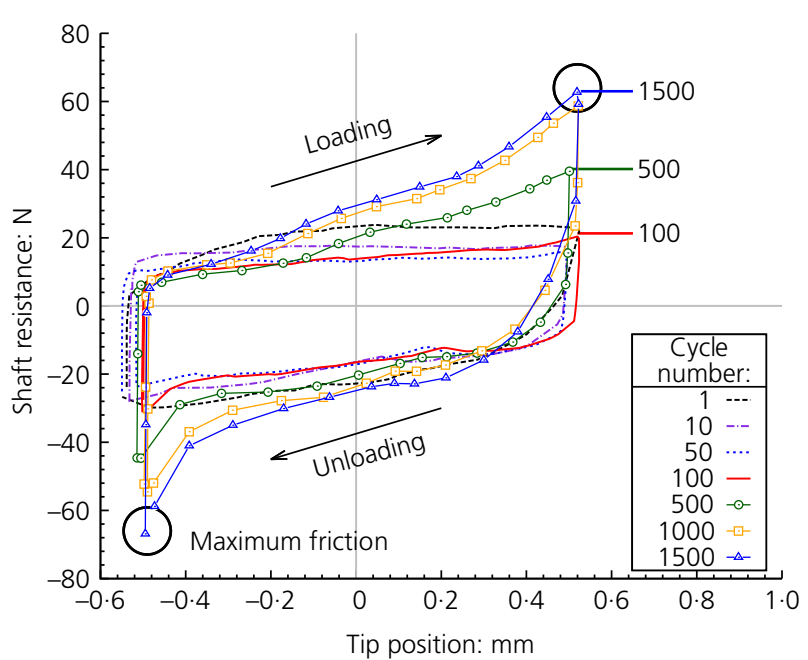

(b)

Fig. 2. Evolution of (a) total load and (b) shaft resistance during cycles for GLAG-C1 (black arrows show the loading path)

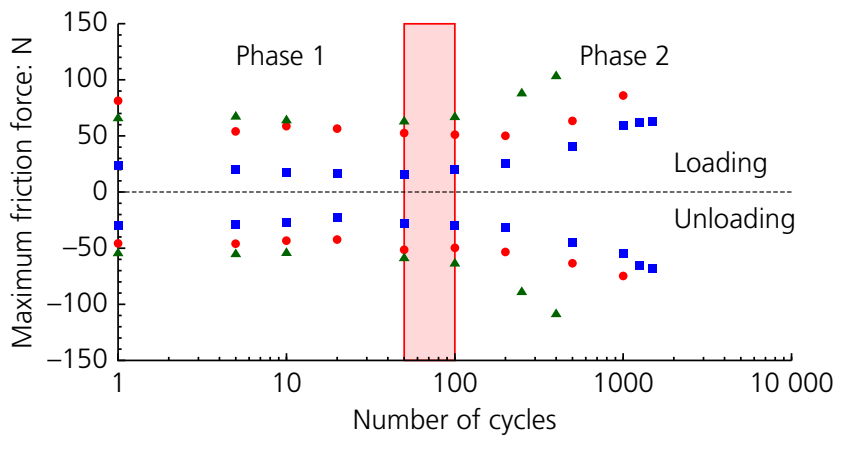

- GLAG-C1 • GLAG-C2 ^ GLAG-C3

Fig. 3. Identification of two phases in shaft resistance evolution (transition between 50 and 100 cycles noted by the shaded region)

the transition between the two phases was found around 3000 cycles and 300 cycles, respectively, for an amplitude of cycle of $\pm 0.5 \mathrm{~mm}$. The difference in the required number of cycles to gain shaft resistance is likely due to the size effects discussed in Section 'Scale Effects'.

\section{X-RAY TOMOGRAPHY AND 3D-DIC}

The loading on the pile is stopped after given amounts of cycles $(1,50,100,500$ and 1000$)$ for 3D scanning. Restricted by the sample size, scans are taken in 'local' tomography, that is, with a field of view focused on the tip and the shaft, for a pixel size of $40 \mu \mathrm{m}$ (which means that there are about 25 pixels across a grain diameter). The X-ray beam is set to a tension of $150 \mathrm{kV}$ and a current of $200 \mu \mathrm{A}$. Figure 4(a) shows a $3 \mathrm{D}$ rendering after pile installation.

3D fields of displacement and strain can be obtained using the 3D-DIC code, TomoWarp2 (Tudisco et al., 2017). 3D-DIC is a powerful tool for assessing the spatial transformation between two digital images, here tomographies. A group of grains within a subdomain, commonly called correlation window (containing about 8 grains in the present case), is tracked from one configuration to another. 3D-DIC was successfully used to study the installation of a pile in sand (Silva \& Combe, 2014). The results, fully three-dimensional, showed distinct regions where grains

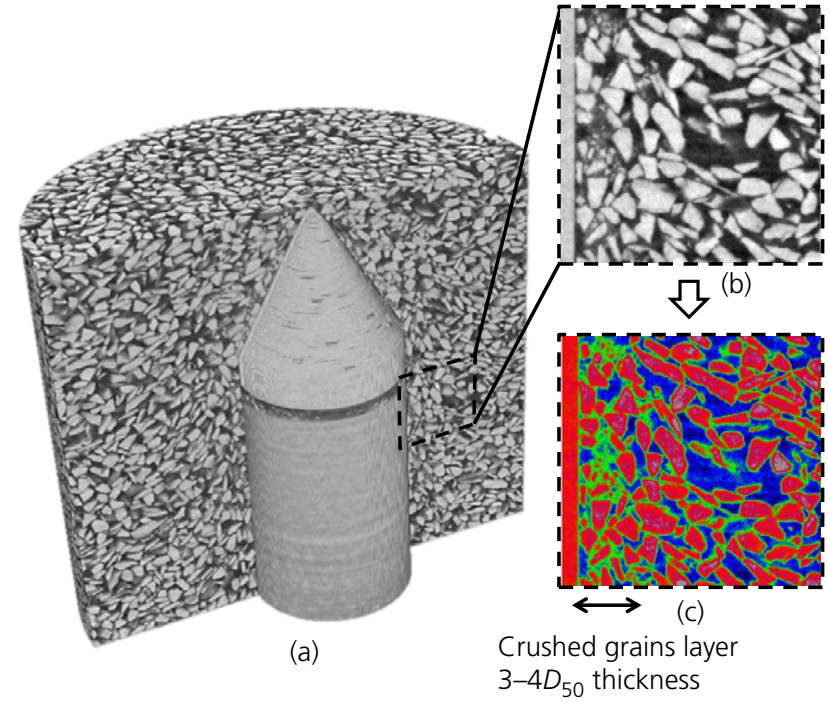

Fig. 4. (a) 3D reconstructed volume after pile installation. (b) Zoom on the interface. (c) Detection of different phases (blue $=$ pores, red = intact grains and green = fines)

rearrangement concentrates. A 'recirculation' of sand grains was also observed close to the tip during the penetration of the pile.

In this work, a discrete version of TomoWarp2, developed at Laboratoire $3 \mathrm{SR}$, is used, which allows for the measurement of the kinematics of each individual sand grain in the sample.

\section{RESULTS AT THE GRAIN SCALE \\ Grain kinematics}

In the following, only the results from test GLAG-C2 are shown, as the results from the other two tests are essentially the same. Typical results from 3D-DIC are presented in Fig. 5 (note that all displacements are measured after pile installation). Two pairs of 3D images are analysed, one from 10 to 50 cycles and one from 500 to 1000 cycles. Note that these two increments, respectively, fall in the first and second phase of behaviour of the shaft resistance defined in Section 'Macroscopic Response of the Interface'. Cyclic loading induces significant displacements, mainly in the horizontal 


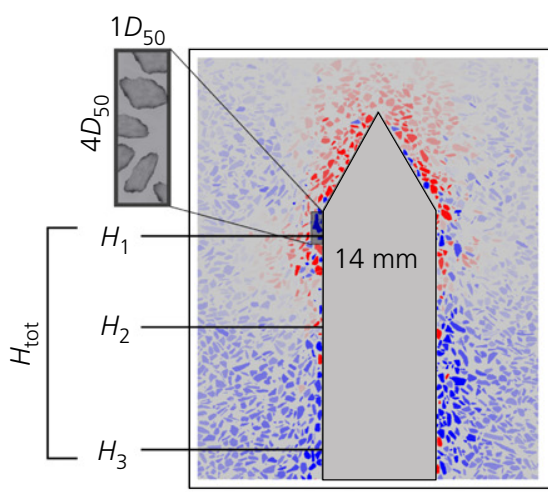

(a)

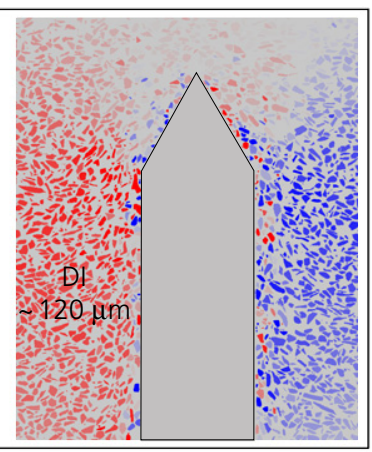

(b)

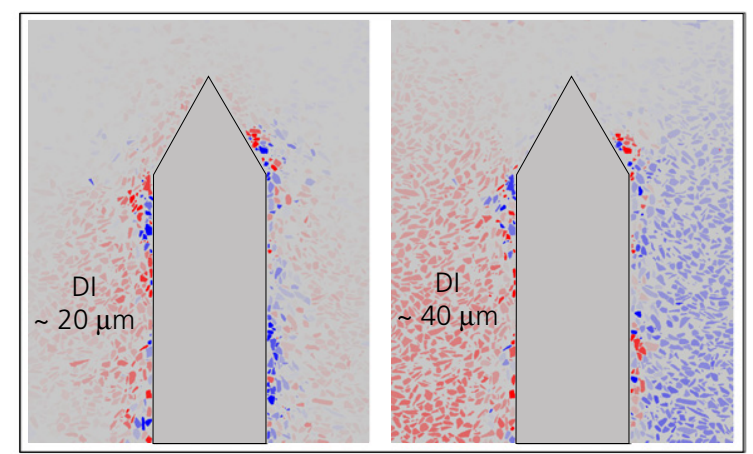

(c) (d)

$160 \mu \mathrm{m}$

Displacement intensity (DI)

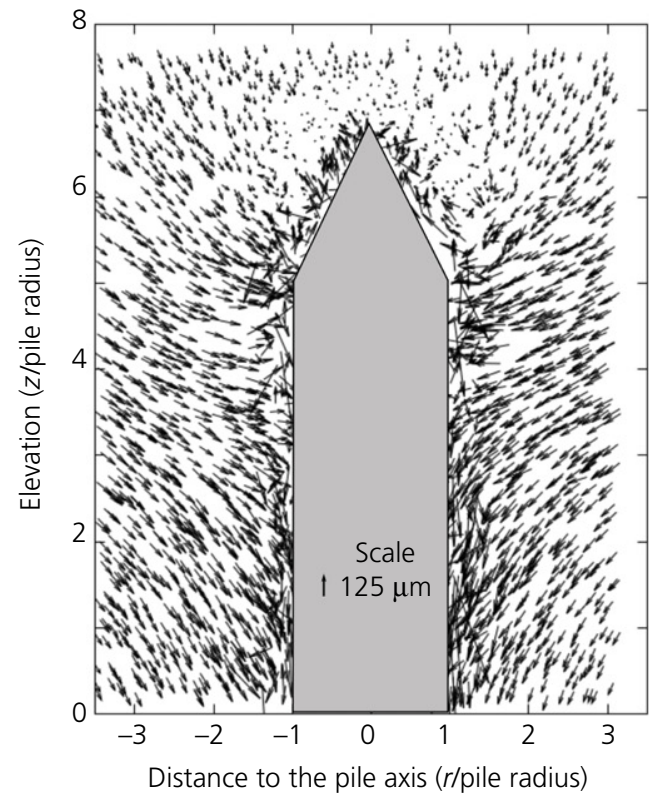

(e)

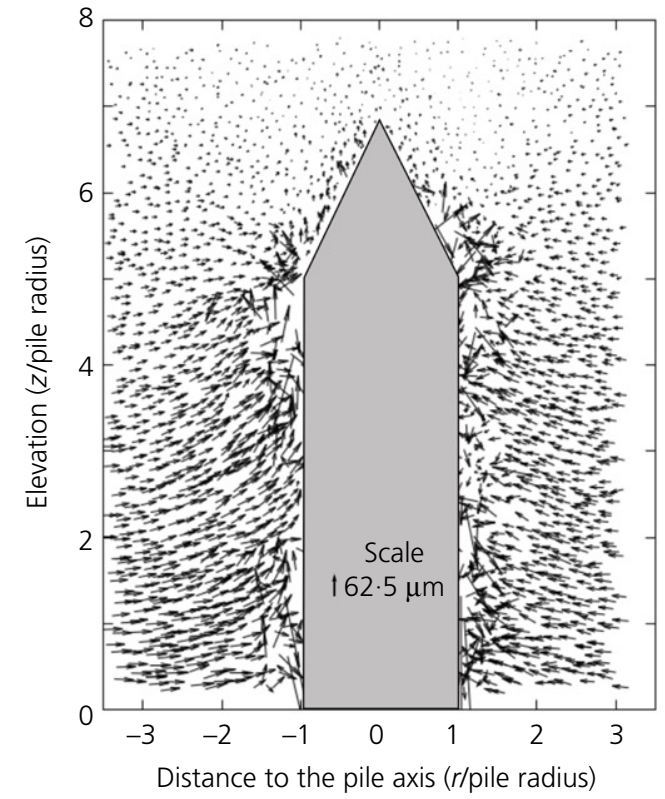

(f)

Fig. 5. Typical individual grain displacements from discrete DIC, plotted in a vertical plane passing through the pile axis. Evolution of DI during cycles: (a) vertical displacements, (b) horizontal displacements between cycles 10 and 50, (c) vertical displacements, (d) horizontal displacements between cycles 500 and 1000. Individual displacement vectors (e) between cycles 10 and 50 and (f) between cycles 500 and 1000 (note that the scale is not the same for (e) and (f))

direction. Grains globally move towards the shaft for both loading steps leading to a radial contraction (Figs 5(b) and 5(d)). The sand mass undergoes very little vertical displacements - less than $20 \mu \mathrm{m}$ (Figs 5(a) and 5(c)). Hebeler et al. (2015) investigated the effect of particle shape and size on CPT friction sleeve behaviour over a range of counter-face surface roughness values. They noted that, for a conventional smooth CPT, some key aspects of interface shearing are eliminated, which results in a pure sliding failure mechanism. In this study, sand grains tend to slide alongside the shaft (mainly due to the low roughness of pile shaft); however, relative displacements between grains, that is, grain rearrangement occurs - and is measured - around the pile.

Individual displacement vectors for both loading increments are shown in Figs 5(e) and 5(f). Ahead of the pile tip, the displacement vectors are nearly vertical and relatively minute, while around the shaft the displacement vectors have a much larger radial component. The displacement fields also reveal, in both increments, a thin layer around the shaft where the grains are highly disturbed and difficult to track from one image to another. In the first of the two increments shown (Fig. 5(e)), grains are moving downwards. This is likely due to a reduction of the hoop stresses created during pile installation. This effect is erased in the later increment.

The radial displacements are calculated from vertical and horizontal displacements using the axis of the pile as the axis of reference. The axisymmetry of the displacement field is verified by calculating the standard deviation of the vertical and horizontal displacements on the circumference of the sample. Radial displacements are averaged within a subdomain (see Fig. 5) defined by its distance from the shaft $(d)$, normalised by $D_{50}$. Three such sub-domains are studied, at three different elevations $\left(H_{1}, H_{2}\right.$ and $H_{3}$ in Fig. 5(a)). Finally, the analysis is also applied to the entire length of the pile $\left(H_{\text {tot }}\right.$ in Fig. 5(a)).

In Fig. 6, average radial displacements are plotted against the normalised distance from the shaft surface. At a distance between 3 and $6 D_{50}$, the highest radial displacements take place. As one goes closer to the shaft, grains displacements decrease significantly. This region corresponds to a layer of 


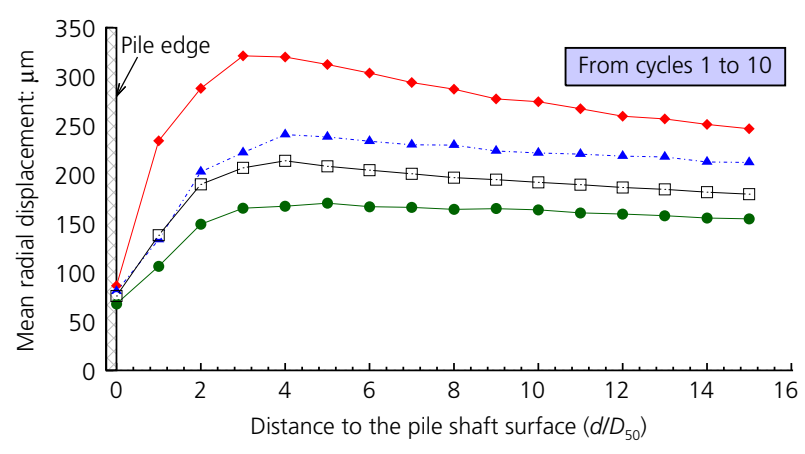

$\because H_{1} \quad \backsim H_{2} \quad \bullet H_{3} \quad \neg-H_{\text {tot }}$

(a)

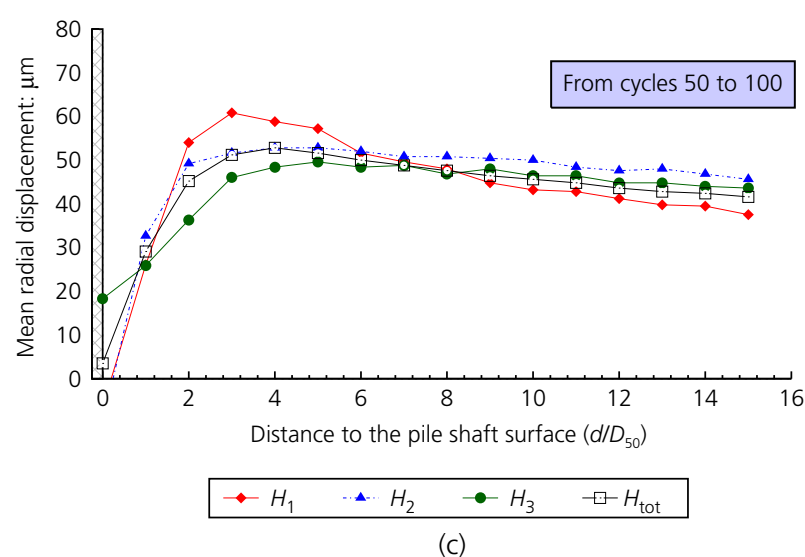

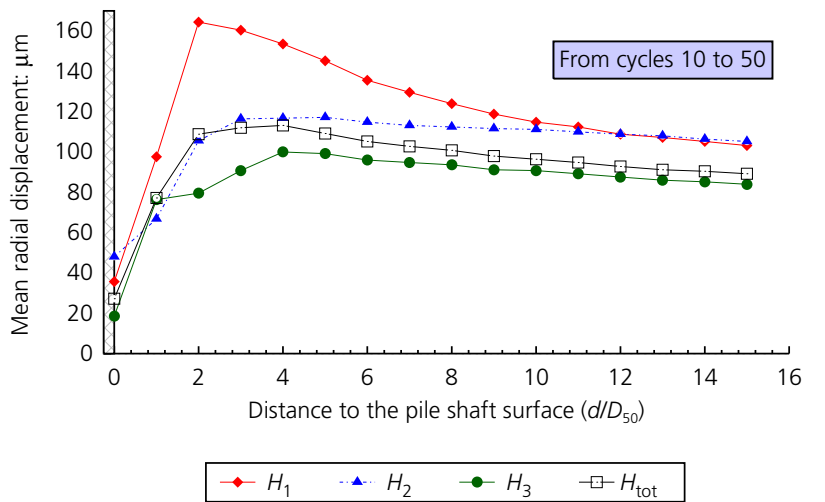

(b)

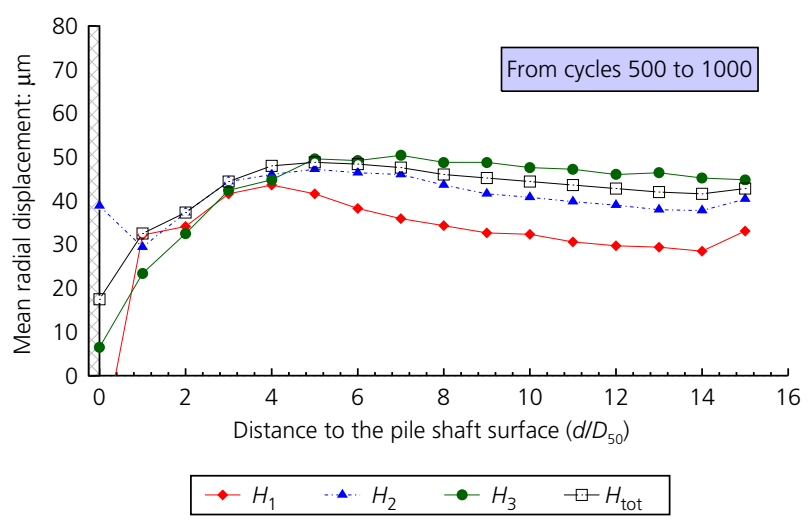

(d)

Fig. 6. Mean radial displacements obtained from discrete DIC for different loading stages: (a) cycles 1-10, (b) cycles 10-50, (c) cycles 50-100 and (d) cycles 500-1000. Radial displacements are averaged within a toroidal subdomain of soil obtained by revolution of the rectangular cross-section shown in Fig. 5(a)

soil experiencing intense shearing, particle crushing and high porosity changes (see Section 'Porosity changes at the interface'). On the shaft surface, non-zero displacements are measured which are likely due to the rotation of the grains induced by shearing. At a distance greater than $6 D_{50}$, sand grains are moving homogeneously towards the shaft. It is also noteworthy that the closer the grains are to the tip (elevation $H_{1}$ ), the more they are affected by the loading. By comparing radial displacements after 50 cycles (Fig. 6(b)) and 1000 cycles (Fig. 6(d)), two different trends can be identified. The first tens of cycles cause higher grain movements (100-300 $\mu \mathrm{m})$. After 50 cycles, displacement intensity (DI) is almost divided by 6 and it is essentially the same at all elevations. Figure 7 shows that the standard deviation of the radial displacements is 20 times higher for the grains close to the pile $\left(d \leq 3 D_{50}\right)$. Except for these grains, kinematics are inhibited after 50 cycles.

\section{Porosity changes at the interface}

$\mathrm{X}$-ray images are analysed looking at the grey levels in order to assess the effect of cycles on porosity. The study is carried out using the open-source image processing software Fiji (see Schindelin et al., 2012). Three phases are identified in the images as shown in Fig. 4(c): pores (low grey level), intact grains (high grey level) and fines produced by grain crushing. These fines are smaller than the pixel size, therefore, they cannot be resolved at the spatial resolution of the images. However, they can be associated with an intermediate mean grey level. Choosing appropriate values for the grey level thresholds, the percentage of voxels belonging to each phase is estimated within 5-voxels-thickness hollow cylinders

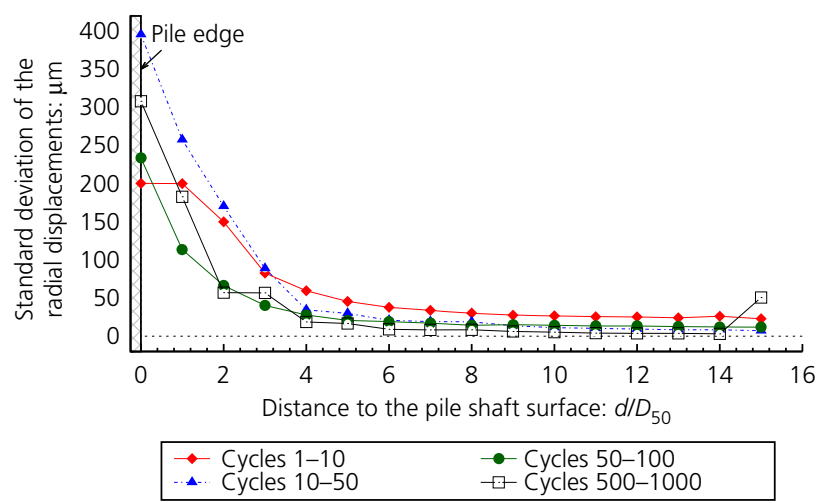

Fig. 7. Evolution of the standard deviation of the radial displacements shown in Fig. 6 for the elevation $H_{1}$ during cycles

centred on the pile axis. The radial evolution of the density of each phase during cyclic loading is plotted in Fig. 8.

The results show an increase of the percentage of voxels associated to intact grains (without taking fines into account) with increasing number of cycles. Close to the interface, the quantity of grains is $20 \%$ higher after 1000 cycles, which indicates a local densification. It can also be observed that the region affected by such densification is about $2 D_{50}$ for cycle 1 and $4 D_{50}$ for cycle 1000 . In the rest of the sand mass, the proportion of grains and pores remains constant. This result indicates that the thickness of the band adjacent to the shaft is related to the displacements that the grains undergo and to the local shearing loading history. Yang et al. (2010) also report a shear zone $2 \cdot 4 D_{50}-8 \cdot 6 D_{50}$ wide, after cyclic jacking installation, in their large 


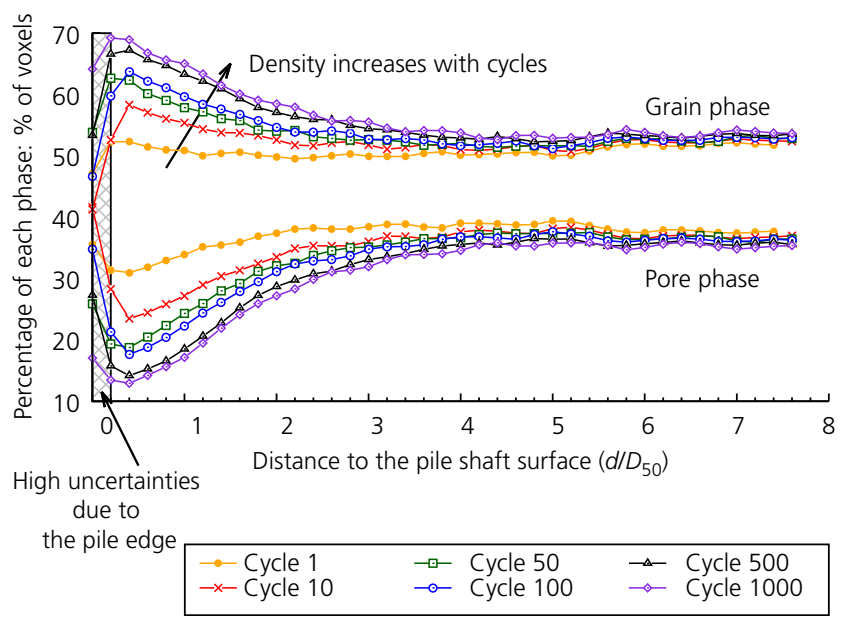

Fig. 8. Radial evolution of intact grain (without fines) and pore phases during cycles for GLAG-C2 (scale: $d=7 D_{50}=$ pile radius). For a given curve, each symbol represents one measurement obtained by image thresholding at a given distance from the shaft
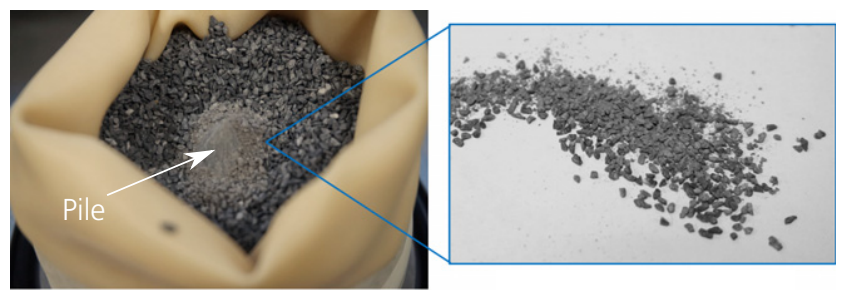

(a)

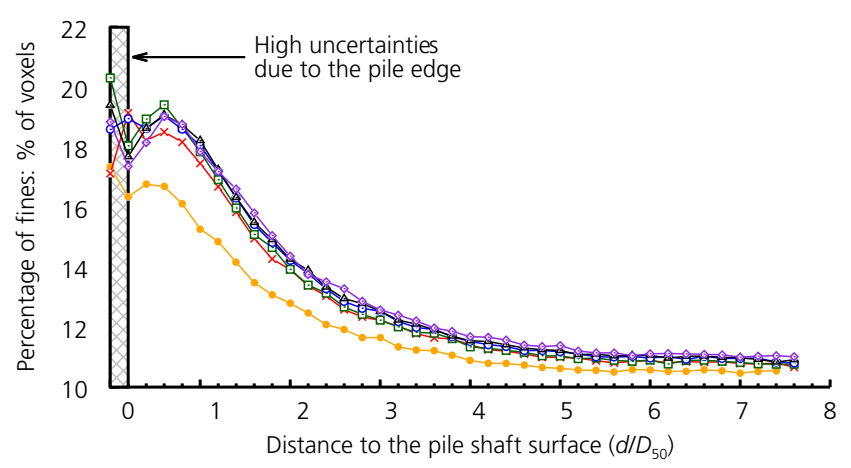

$\begin{array}{lll}\rightarrow-\text { Cycle } 1 & \rightarrow-\text { Cycle } 50 & \rightarrow \text { Cycle } 500 \\ \rightarrow-\text { Cycle } 10 & \rightarrow-\text { Cycle } 100 & \rightarrow \text { Cycle } 1000\end{array}$

(b)

Fig. 9. Grain crushing study: (a) in light grey (top left picture), crushed grains recovered post-mortem at the interface and (b) evolution of fines quantity during cycles for GLAG-C2

calibration chamber tests on NE34 Fontainebleau sand $\left(D_{50}=0.21 \mathrm{~mm}\right)$. Similar to Silva et al. (2013), in their post-mortem analysis, Yang et al. (2010) suggest that the shear zone thickness grows with the vertical distance from the pile tip, especially when the installation is not monotonic, and is augmented by later static or cyclic loading.

\section{Grain crushing}

Figure 4(b) shows a layer of crushed grains about $4 D_{50}$ wide at the interface - see also post-mortem pictures in Fig. 9(a). The powder resulting from grain crushing is highly packed and fills the pores between intact grains. Figure 9(b) shows that fines production increases to about $2 \%$ between the first and tenth cycle. Due to their own weight, fines rearrange around the shaft during the first loading and unloading steps, which may explain this apparent increase of the quantity of fines. For a larger amount of cycles, the percentage of fines remains stable, indicating that most of particle crushing occurred during pile installation.

\section{CONCLUSIONS}

The influence of axial cyclic loading on the behaviour of sand-pile interface has been analysed at the grain scale thanks to X-ray tomography and advanced 3D image analysis. Two distinct phases are identified in the evolution of shaft resistance, according to the number of applied cycles. For these two phases, the measurement of grain kinematics reveals a different behaviour of the sand mass associated with a significant densification at the interface. In the first phase, the sand mass contracts radially within a region of thickness $4 D_{50}$. This mechanism is likely due to inter-granular rearrangement. In the second phase, sand grains hardly move and the sand mass reaches a threshold density for which the friction on the shaft starts to substantially increase.

In this experimental study, the test conditions are admittedly not representative of true field conditions. In fact, some of the results obtained in this study cannot (and should not) be directly extrapolated to field cases. For example, the positive effect of cyclic loading on shaft resistance is a clear consequence of the very specific way loading cycles are applied (full failure displacement-controlled) which is rarely the case in the field. However, due to welldefined and fully known testing conditions, the model pile tests presented in this study provide valuable results, which can be used to validate theoretical solutions or numerical models.

The way a pile is installed has a major effect on its mechanical behaviour (Deeks et al., 2005; Li et al., 2012). Thus, the next steps of this research will include the use of different modes of pile installation, in order to isolate (and better understand) the various mechanisms controlling the macroscopic behaviour of sand-pile interface, that is, grain rearrangement, dilatancy/contractancy, grain crushing and production of fines.

\section{ACKNOWLEDGEMENTS}

The authors gratefully acknowledge Pascal Charrier, Christophe Dano, Matías Silva and Edward Andò, from Laboratoire 3SR, for their contributions. They also thank the three reviewers for their extremely valuable suggestions. Laboratoire 3SR is part of the LabEx Tec 21 (Investissements d'Avenir - grant agreement number ANR11-LABX-0030).

\section{REFERENCES}

Arshad, M. I., Tehrani, F. S., Prezzi, M. \& Salgado, R. (2014). Experimental study of cone penetration in silica sand using digital image correlation. Géotechnique 64, No. 7, 551-569.

Been, K., Crooks, J., Becker, D. \& Jefferies, M. (1986). The cone penetration state parameter test in sands: part I, interpretation. Géotechnique 36, No. 2, 239-249.

Bekki, H., Tali, B., Canou, J., Dupla, J. C. \& Bouafia, A. (2016). Influence of the cyclic loading of very large number of cycles on the pile capacity. J. Appl. Eng. Sci. Technol. 2, No. 2, 51-55.

Benzaria, O., Puech, A. \& Le Kouby, A. (2013). Essais cycliques axiaux sur des pieux forés dans des sables denses. In Proceedings 18th ICSMGE, pp. 2323-2326. Paris, France: Presses des Ponts (in French). 
Boulon, M. \& Foray, P. (1986). Physical and numerical simulation of lateral shaft friction along offshore piles in sand. In Proceedings of the 3rd international conference on numerical methods in offshore piling, pp. 127-147. Paris, France: Technip.

Butlanska, J., Arroyo, M., Gens, A. \& OSullivan, C. (2014). Multi-scale analysis of cone penetration test (CPT) in a virtual calibration chamber. Can. Geotech. J. 51, No. 1, 5166.

Deeks, A. D., White, D. J. \& Bolton, M. D. (2005). A comparison of jacked, driven and bored piles in sand. In Proceedings of the 16th international conference on soil mechanics and geotechnical engineering, Osaka, Japan, vol. 3, pp. 2103-2106. Rotterdam, the Netherlands: Millpress Science Publishers.

Fioravante, V. (2002). On the shaft friction modelling of nondisplacement piles in sand. Soils Found. 42, No. 2, 23-33.

Foray, P. (1991). Scale and boundary effects on calibration chamber pile tests. In Proceedings of the 1st international symposium on calibration chamber testing, Potsdam, NY, USA (ed. A. B. Huang), pp. 147-160. New York, NY, USA: Elsevier.

Hebeler, G. L., Martinez, A. \& Frost, J. D. (2015). Shear zone evolution of granular soils in contact with conventional and textured CPT friction sleeves. KSCE J. Civil Engng 20, No. 4, $1267-1282$.

Jardine, R. J. \& Standing, J. R. (2000). Pile load testing performed for HSE cyclic loading study at Dunkirk, France. Vols 1 and 2 , Offshore Technology Report OTO 2000 007. London, UK: Health and Safety Executive.

Jardine, R. J. \& Standing, J. R. (2012). Field axial cyclic loading experiments on piles driven in sand. Soils Found. 52, No. 4, $723-737$.

Jiang, M. J., Yu, H. S. \& Harris, D. (2006). Discrete element modelling of deep penetration in granular soils. Int. J. Numer. Anal. Methods Geomech. 30, No. 4, 335-361.

Lee, J., Prezzi, M. \& Salgado, R. (2011). Experimental investigation of the combined load response of model piles driven in sand. Geotech. Test. J. 34, No. 6, 653-667.

Li, Z., Bolton, M. D. \& Haigh, S. K. (2012). Cyclic axial behaviour of piles groups in sand. Can. Geotech. J. 49, No. 9, 1074-1087.

Lobo-Guerrero, S. \& Vallejo, L. E. (2007). Influence of pile shape and pile interaction on the crushable behavior of granular materials around driven piles: DEM analyses. Granular Matter 9, No. 3-4, 241-250.

Parkin, A. \& Lunne, T. (1982). Boundary effects in the laboratory calibration of a cone penetrometer in sand. In Proceedings of the 2nd European symposium on penetration testing, Amsterdam, the Netherlands, vol. 2, pp. 761-768. Rotterdam, the Netherlands: CRC Press.

Peterson, R. W. (1988). Laboratory investigation of the penetration resistance of fine cohesionless materials. In Proceedings of the 1st international symposium on penetration testing, Orlando, FL, USA, pp. 875-880. Rotterdam, the Netherlands: Balkema.

Rimoy, S., Silva, M., Jardine, R., Yang, Z. X., Zhu, B. T. \& Tsuha, C. H. C. (2015). Field and model investigations into the influence of age on axial capacity of displacement piles in silica sands. Géotechnique 65, No. 7, 576-589, https://doi.org/ 10.1680/geot.14.P.112.

Salgado, R., Mitchel, J. K. \& Jamiolkowski, M. (1998). Calibration chamber size effects on penetration resistance in sand. J. Geotech. Geoenviron. Engng 124, No. 9, 878-888.

Schindelin, J., Arganda-Carreras, I. \& Frise, E. (2012). Fiji: an open-source platform for biological-image analysis. Nature methods 9, No. 7, 676-682.

Schnaid, F. \& Houlsby, G. (1991). An assessment of chamber size effects in the calibration of in situ tests in sand. Géotechnique 41, No. 3, 437-445.

Silva, M. (2014). Experimental study of ageing and axial cyclic loading effect on shaft friction along driven piles in sand. $\mathrm{PhD}$ thesis, Université de Grenoble, Grenoble, France.

Silva, M. \& Combe, G. (2014). Sand displacement field analysis during pile installation using X-ray tomography and digital image correlation. In Proceedings of the international symposium on geomechanics from micro to macro, Cambridge, UK, vol. 1, pp. 1599-1603. Leiden, the Netherlands: CRC Press.

Silva, M., Combe, G., Foray, P. Y., Flin, F. \& Lesaffre, B. (2013). Postmortem analysis of sand grain crushing from pile interface using X-ray tomography. Proceedings of the powders and grains 2013, vol. 1542, p. 297. Sydney, Australia: UNSW.

Tehrani, F. S., Han, F., Salgado, R., Prezzi, M., Tovar, R. D. \& Castro, A. G. (2016). Effect of surface roughness on the shaft resistance of non-displacement piles embedded in sand. Géotechnique 66, No. 5, 386-400.

Tsuha, C. H. C., Foray, P. Y., Jardine, R. J., Yang, Z. X., Silva, M. \& Rimoy, S. (2012). Behaviour of displacement piles in sand under cyclic axial loading. Soils Found. 52, No. 3, 393-410.

Tudisco, E., Andò, E., Cailletaud, R. \& Hall, S. A. (2017). A local digital volume correlation code. Software XC 6, 267-270.

Uesugi, M., Kishida, H. \& Tsubakihara, Y. (1988). Behavior of sand particles in sand-steel friction. Soils Found. 28, No. 1, $107-118$.

White, D. J. \& Bolton, M. D. (2002). Observing friction fatigue on a jacked pile. In Constitutive and Centrifuge Modeling: Two Extremes (ed. S. M. Springman), pp. 347-354. Rotterdam, the Netherlands: Balkema.

Yang, Z. X., Jardine, R., Zhu, B., Foray, P. \& Tsuha, C. (2010). Sand grain crushing and interface shearing during displacement pile installation in sand. Géotechnique 60, No. 6, $469-482$.

\section{HOW CAN YOU CONTRIBUTE?}

To discuss this paper, please submit up to 500 words to the editor at journals@ice.org.uk. Your contribution will be forwarded to the author(s) for a reply and, if considered appropriate by the editorial board, it will be published as a discussion in a future issue of the journal. 